\title{
An Investigation on the Dependency of Bursting Strength of Knitted Fabrics on Knit Structures
}

Dereje Berihun Sitotaw*

Bahir Dar University, Bahir Dar, Amhara, Ethiopia

\begin{abstract}
Knitted fabrics bursting strength dependency was investigated. The investigation was by reviewing previously done and published research articles. In this investigation the dependency of bursting strengths on knit structures was identified and analyzed. Different findings of different scholars on bursting strengths of different knitted fabrics have been discussed in this review.
\end{abstract}

Keywords: Bursting strength; Knit structures; Dependency

\section{Introduction}

Strength of the fabric is an important property that decides and influences all other performance properties of the knitted fabrics. Consideration of the strength of the fabric is very essential while selecting the appropriate fabric for the intended garment [1]. The physical and mechanical properties of knitted fabrics are very important in many ways. Among these properties, the bursting strength is extremely important. Bursting strength is the force that must be exerted perpendicularly to the fabric surface to break off fabric. Bursting strengths of knitted fabrics can be affected by knit structure as investigated by different scholars.

\section{Materials}

The materials used in this review are previously published articles those studied by different scholars.

\section{Methods}

The methods are identifying the most recent publications on bursting strengths of knitted fabrics, selecting the factors which significantly influencing the bursting strength, collections of articles related to bursting strength dependency, deep reading, analyzing, writing the analyzed review and conclude.

\section{Results and Discussion}

\section{Dependency of bursting strength on fabric structure}

Fabric structures have significant effect on bursting strength of knitted fabrics. As Abd El-Hady and Abd El-Baky [2,3] reporting their finding, bursting strength revealed that the effect of knit structure is highly significant in produced fabrics. Fleece fabrics have weaker bursting strength performance compared with plush fabrics due to the tuck and miss loop in these structures. That higher tuck loop presence decreases the bursting strength; Miss Loop also reduces the bursting strength but bursting strength of miss loop containing derivatives is higher than tuck loop containing derivatives. The structures with the higher thickness (Figure 1, Sample No.3) have the higher bursting strength properties for both fleece and plush fabrics. This is most probably due not only to thickness, but also to stitches density (Figure 1). The number and position of tuck stitch has an effect on the bursting strength of knitted fabrics. Uyanik et al. [4] reported the effect of number and location of tuck stitch by investigating twelve samples. As shown in Table 1, the number of tuck stitches found in one knit structure is different from the other. Similarly the position of each tuck stitch is different one from the other. This leads to the variation in the bursting strength of knitted fabrics.

As Uyanik et al. [4] described the number and locations of tuck stitches of the sample knitted fabrics are different from each other. To see the effect of the number and location of tuck stitches on the bursting strength of the fabrics, a graph was drawn, in Figure 2.

According to Figure 2 the bursting strength of the sample knitted fabrics changes between approximately 363 to $774 \mathrm{kPa}$. Uyanik et al. [4] conclude that the bursting strength degree of the sample knitted fabrics, the values and patterns are evaluated together. Sample 1 is plain fabric and has no tuck stitch. The bursting strength of this sample is presented as a control group. As seen from Figure 3, the bursting strength of samples 3, 5 and 6 are lower than the others. The pattern designs of tuck stitches in these samples are not zigzag. When the location of tuck stitches are not in a zigzag form, the fabric will not pick up very much; in other words the loops inside the fabrics do not come together very much. Then the tightness of the structure is low, and hence the resistances of the fabrics to air pressure decreased

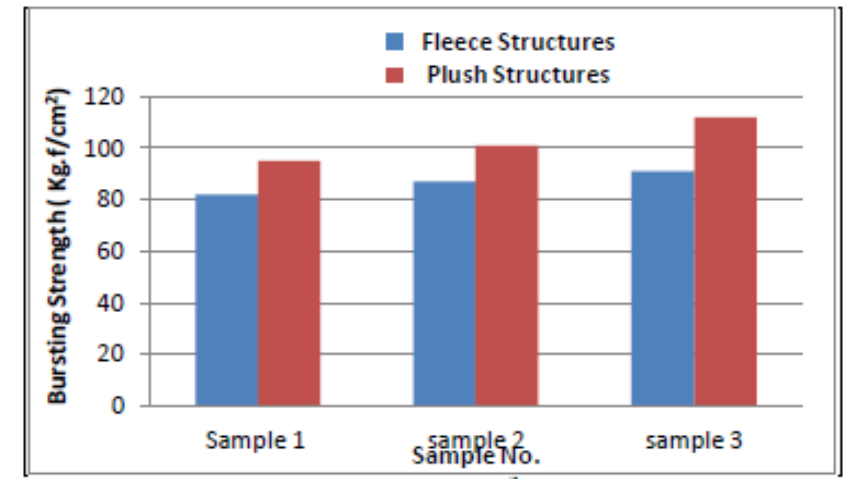

Figure 1: Bursting Strength $\left(\mathrm{Kg} . \mathrm{f} / \mathrm{cm}^{2}\right)$ for produced samples.

*Corresponding author: Dereje Berihun Sitotaw, M.Sc, Bahir Dar University, Bahir Dar, Amhara, Ethiopia, Tel: +251 91835 3494; E-mail: dere96@yahoo.com

Received April 13, 2017; Accepted May 04, 2017; Published May 12, 2017

Citation: Sitotaw DB (2017) An Investigation on the Dependency of Bursting Strength of Knitted Fabrics on Knit Structures. Ind Eng Manage 6: 221. doi:10.4172/2169-0316.1000221

Copyright: (c) 2017 Sitotaw DB. This is an open-access article distributed under the terms of the Creative Commons Attribution License, which permits unrestricted use, distribution, and reproduction in any medium, provided the original author and source are credited. 
Citation: Sitotaw DB (2017) An Investigation on the Dependency of Bursting Strength of Knitted Fabrics on Knit Structures. Ind Eng Manage 6: 221. doi:10.4172/2169-0316.1000221

Page 2 of 4

\begin{tabular}{|c|c|c|c|c|c|}
\hline Sample No. & Pattern properties & Needle diagram & Sample No & Pattern properties & Needle diagram \\
\hline 1 & $\begin{array}{l}\text { This sample is named single jersey and it has } \\
\text { no tuck stitch }\end{array}$ & 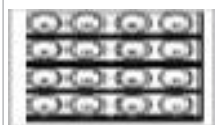 & 2 & $\begin{array}{l}\text { This sample is a combination of } \\
\text { sample } 4 \text { with } 48 \text { courses and } \\
\text { sample } 1 \text { with } 36 \text { courses. }\end{array}$ & \\
\hline 3 & $\begin{array}{l}\text { This sample is a combination of sample } 6 \text { with } \\
54 \text { courses and sample } 1 \text { with } 30 \text { courses. }\end{array}$ & & & $\begin{array}{l}\text { This sample is named "honeycomb" } \\
\text { and it has } 4 \text { tuck stitches in the same } \\
\text { needle. This type is known as zigzag } \\
\text { pattern. }\end{array}$ &  \\
\hline 5 & $\begin{array}{l}\text { This sample has } 2 \text { tuck stitches and } 1 \text { plain } \\
\text { stitch in the same needle. }\end{array}$ & 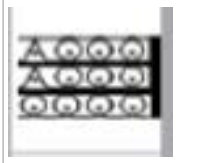 & & $\begin{array}{l}\text { This sample has } 4 \text { stuck stitches in } \\
\text { the same needle }\end{array}$ & 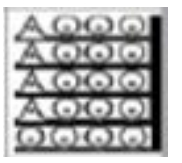 \\
\hline 7 & $\begin{array}{l}\text { This sample is named "honeycomb" and it has } \\
5 \text { tuck stitches } 1 \text { plain stitch in the same needle. } \\
\text { This type is known as zigzag pattern. }\end{array}$ & 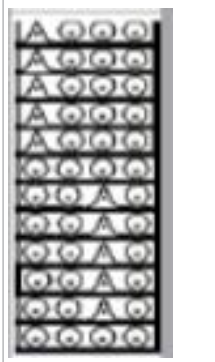 & & $\begin{array}{l}\text { This sample is named "single } \\
\text { lacoste" and it has } 1 \text { tuck stitch and } 1 \\
\text { palin stitch in the same needle. This } \\
\text { type is known as zigzag pattern }\end{array}$ & \\
\hline 9 & $\begin{array}{l}\text { This sample is named "double lacoste" and it } \\
\text { has } 2 \text { tuck stitches } 1 \text { plain stitch in the same } \\
\text { needle. This type is known as zigzag pattern. }\end{array}$ & $\frac{Q 2}{82}$ & & $\begin{array}{l}\text { This sample has } 2 \text { tuck stitches in } \\
\text { the adjacent needles for the } 1^{\text {st }} \text { and } \\
2^{\text {nd }} \text { courses and then } 1 \text { tuck stitch } \\
\text { in the other needles for the } 3^{\text {rd }} \text { and } \\
4^{\text {th }} \text { courses. This type is known as } \\
\text { zigzag pattern }\end{array}$ & $\frac{0.262}{\frac{0.26}{802}}$ \\
\hline 11 & $\begin{array}{l}\text { This sample is named "English plque" and it has } \\
2 \text { tuck stitches but no plain stitch in the same } \\
\text { needle. This type is known as zigzag pattern. }\end{array}$ & $\frac{\mathrm{A} Q \mathrm{a}}{\mathrm{A} \Omega 2}$ & & $\begin{array}{l}\text { This sample has } 2 \text { tuck stitches in } \\
\text { the adjacent needles for the } 1^{\text {st }} \text { and } \\
2^{\text {nd }} \text { courses and then } 1 \text { tuck stitch } \\
\text { in the other needles for the } 3^{\text {rd }} \text { and } \\
4^{\text {th }} \text { courses. This type is known as } \\
\text { zigzag pattern. }\end{array}$ & 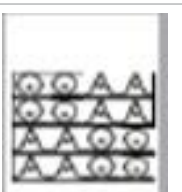 \\
\hline
\end{tabular}

Table 1: Pattern properties and needle diagrams of samples.

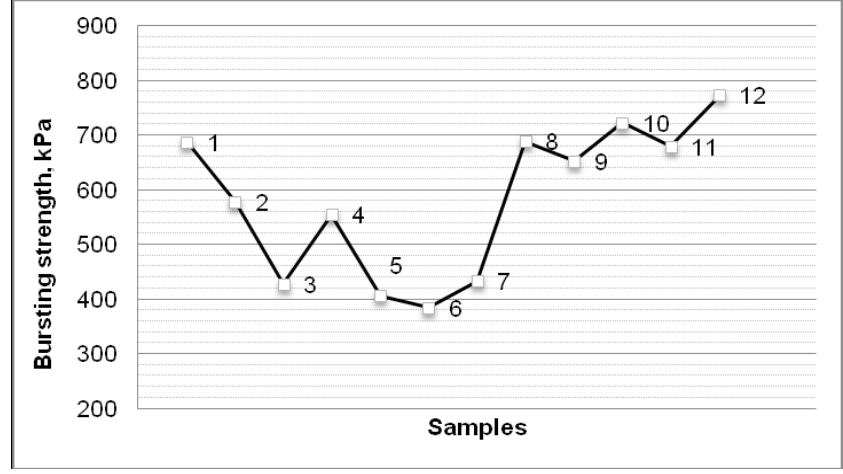

Figure 2: Bursting strength of gray fabrics according to the number and location of tuck stitches.

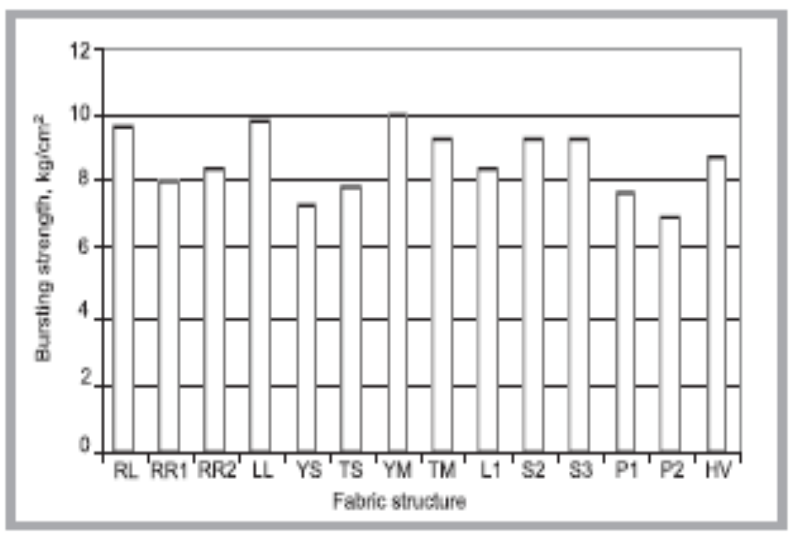

Figure 3: Effects of knit structure on bursting strength for washed fabrics 
Citation: Sitotaw DB (2017) An Investigation on the Dependency of Bursting Strength of Knitted Fabrics on Knit Structures. Ind Eng Manage 6: 221. doi:10.4172/2169-0316.1000221

Page 3 of 4

and the bursting strength of these samples is low. Especially with an increasing number of tuck stitches, the width of the fabric increases and the slackness of the structure grow. Therefore the bursting strength of sample 6 is lower than the others.

In the honeycomb patterns, which have zigzag structures, the tightness of the fabric is high. Bursting strength values of the honeycomb patterned fabrics are high too, but in these patterns the loops come together lengthwise, and while the length of the fabric decreases, the width of the fabric increases. Therefore in these patterns the fabric does not pick up as the other zigzag structured fabrics. The difference is seen clearly in numbered samples 4 and 7 . Although their repeat is the same, in sample 7 there are five tuck stitches over one needle; while there are four tuck stitches in samples 4 (Table 1). As a result, sample 7 expands widthwise more than sample 4 , and the toughness of the sample decreases; therefore the bursting strength of sample 7 is lower than that of sample 4 .

In the samples with a zigzag structure whose repeats in the lengthwise and widthwise direction is short, the fabrics are extremely tough due to the effect of tuck stitches, which increases the bursting strength of the fabrics. The bursting strength values of samples $8,9,10$, 11 and 12 are very close to that of sample 1, namely single jersey fabric and notably high. The reason for this situation is the toughness of these samples.

The number of tuck stitches of samples 11 and 12 are the same, but the bursting strength value of sample 12 is higher than that of sample 11. In sample 12, tuck stitches are formed over adjacent needles and tuck stitches transformed to float the loop form at the same time. This float behaves like reinforcement in this sample; thus the bursting strength value of sample 12 increases.

In samples 11 and 10 , the bursting strength value of sample 10 is higher than that of sample 11. The tuck stitches are over adjacent needles in both of the two samples, but the number of tuck stitches of sample 10 is higher than that of sample 11 , and hence there is a difference between two samples.

Emirhanova et al. [5] investigating the effect of knit structures on bursting strength of washed knitted fabrics. As shown in Figure 3, the results of their investigation for bursting strength revealed that the effect of knit structure is highly significant in washed fabrics. Moss stitch and half cardigan fabrics have weaker bursting strength performance. Half Milano, links-links and plain fabrics have the strongest bursting strength performance (Figure 3).

Nassif [6], showed the relationship between knit structures and bursting strength of the knitted fabrics during his study on the effects of machine gauge and some knit structures on the physical properties of weft knitted fabrics. The statistical analysis listed in Table 2 revealed that knit structure and knitting machine gauge have a significant effect on the knitted fabric bursting strength at 0.01 significance level. From Figure 4 it is shown that machine gauge has a positive influence on knitted fabric bursting strength. An increasing trend is detected, assuring that as the machine gauge increases the bursting strength of the knitted fabrics increases. It is also shown that there is significant difference between the fabric structures in relation to its bursting strength. The bursting strength of the knitted fabrics was found to have the following order: Single jersey > Rib > Interlock.

Nassif [6] gives the method to predict the bursting strength of the different knitted fabrics at the different levels of knitting machine gauges, by using the following regression models:

\begin{tabular}{|l|l|l|l|l|l|l|}
\hline $\begin{array}{l}\text { Source of } \\
\text { variation }\end{array}$ & SS & DF & MS & F & P-value & F-crit \\
\hline Knit structure & 18 & 2 & 9 & 10.8 & 0.024414 & 6.944276 \\
\hline $\begin{array}{l}\text { Machine } \\
\text { Gauge }\end{array}$ & 140.6667 & 2 & 70.3333 & 84.4 & 0.000536 & 6.944276 \\
\hline Error & 3.3333 & 4 & 0.8333 & & & \\
\hline Total & 162 & 8 & & & & \\
\hline
\end{tabular}

Table 2: Effect of knit structures and machine gauge on bursting strength of knitted fabrics (ANOVA).

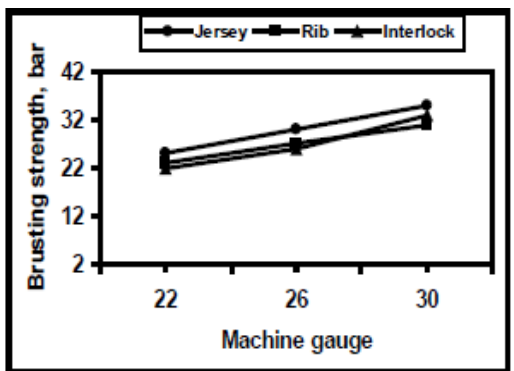

Figure 4: Effect of knitting machine gauge on knitted fabric Bursting strength for different knit structures.

\begin{tabular}{|l|c|c|}
\hline \multirow{2}{*}{ Fabric Type } & \multicolumn{2}{|c|}{ Bursting Strength(PSI) } \\
\cline { 2 - 3 } & Grey & Finish \\
\hline Single jersey & 90 & 77 \\
\hline Single Pique & 72 & 61 \\
\hline Double Pique & 61 & 49 \\
\hline
\end{tabular}

Table 3: Bursting strength of pique fabrics.

\begin{tabular}{|l|c|c|}
\hline \multirow{2}{*}{ Fabric Type } & \multicolumn{2}{|c|}{ Bursting Strength(PSI) } \\
\cline { 2 - 3 } & Grey & Finish \\
\hline Single jersey & 90 & 77 \\
\hline Single Lacoste & 77 & 60 \\
\hline Double Lacoste & 71 & 56 \\
\hline
\end{tabular}

Table 4: Bursting strength of lacoste fabrics.

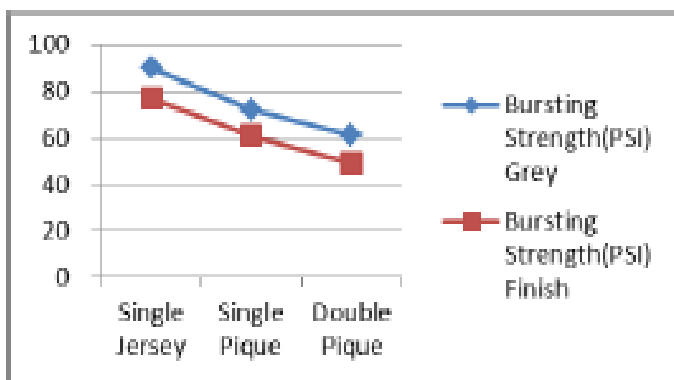

Figure 5: Bursting strength of pique fabrics

Bursting strength, bar (for single jersey) $=5 \times$ gauge +20

Bursting strength, bar (for Rib) $=4 \times$ gauge +19

Bursting strength, bar $($ for Interlock $)=5.5 \times$ gauge +16 .

He found the coefficient of determination values for these models 1,1 and 0.97 for single jersey, rib and interlock structures respectively.

Islam [7], Effect of Tuck Loops on Bursting Strength: Tables 3, 4, Figures 5 and 6 shows that bursting strength of pique design is lower than lacoste structure. In case of pique fabric (Table 3 and Figure 5), it was observed that with the increasing of tuck loops bursting strength 
Citation: Sitotaw DB (2017) An Investigation on the Dependency of Bursting Strength of Knitted Fabrics on Knit Structures. Ind Eng Manage 6: 221. doi:10.4172/2169-0316.1000221

Page 4 of 4

decreases [8-10]. Grey and finish bursting strength of single pique (72 and 61 PSI) was found higher than double pique (61 and 49 PSI). Same result was found for lacoste fabrics; with the increasing of tuck loops bursting strength decreases where single lacoste grey and finish bursting strength (77 and 60 PSI) was higher than double lacoste (71 and 56 PSI) (Table 4 and Figure 6). On other hand, Grey and finish bursting strength of double pique was 61 and 49 in PSI whereas bursting strength of double lacoste design was 71 and 66 PSI [11]. It means all knit course insertion on double pique design increases the bursting strength. For all structures finish bursting strength was lower than grey bursting strength. It was also observed that involvedness of tuck loops decreases the bursting strength.

Effect of Miss Loops on Bursting Strength: Tables 5, 6, Figures 7 and 8 indicate that after finishing bursting strength decreases for every observation. But the decrement of bursting strength in case of cross miss design is higher than locknit designs [12,13]. Increasing of miss loops also reduces the bursting strength because single cross miss design shows the grey strength and finish strength as 73 and 63 PSI where double cross miss design shows 66 and 55 PSI (Table 5 and Figure 7). Same result found for locknit designs where single locknit designs shows 80 and 72 PSI in grey and finish state and double locknit



Figure 6: Bursting strength of lacoste fabrics.

\begin{tabular}{|l|c|c|}
\hline \multirow{2}{*}{ Fabric Type } & \multicolumn{2}{|c|}{ Bursting Strength(PSI) } \\
\cline { 2 - 3 } & Grey & Finish \\
\hline Single jersey & 90 & 77 \\
\hline Single cross miss & 73 & 63 \\
\hline Double cross miss & 66 & 55 \\
\hline
\end{tabular}

Table 5: Bursting strength of cross miss fabrics.

\begin{tabular}{|l|c|c|}
\hline \multirow{2}{*}{ Fabric Type } & \multicolumn{2}{|c|}{ Bursting Strength(PSI) } \\
\cline { 2 - 3 } & Grey & Finish \\
\hline Single jersey & 90 & 77 \\
\hline Single locknit & 80 & 72 \\
\hline Double locknit & 74 & 64 \\
\hline
\end{tabular}

Table 6: Bursting strength of locknit fabrics.

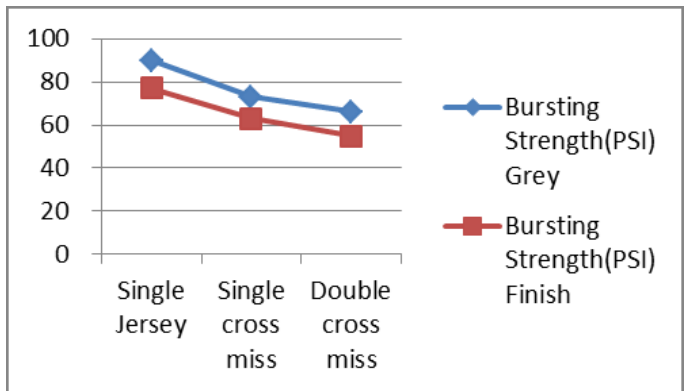

Figure 7: Bursting strength of cross miss fabrics.



Figure 8: Bursting strength of locknit fabrics.

shows 74 and 64 PSI (Table 6 and Figure 8). It can be also discussed that locknit designs have more bursting strength than cross miss designs. It means that all knit course insertion in cross miss designs increases the bursting strength of the fabrics $[14,15]$.

\section{Conclusion}

Bursting strength of different knitted fabrics is dependent up on different factors. In this review we can understand that bursting strengths of knitted fabrics are significantly dependent on fabric structures, fiber types and blends as well as yarns. These factors are the main factors in which bursting strength of knitted fabrics is dependent.

\section{References}

1. Teli MD, Khare AR, Chakrabarti R (2008) Dependence of yarn and fabric strength on the structural parameters. Autex Research J 8: 63-67.

2. Abd El-Hady RAM, Abd El-Baky RAA (2015) The influence of pile weft knitted structures on the functional properties of winter outerwear fabrics. J American Sci 11: 101-108

3. Abd El-Hady RAM, Abd El-Baky RAA (2015) Performance characteristics of warp knitted lining fabrics used for sportswear. Life Sci J 12: 98-104.

4. Uyanik S, Degirmenci Z, Topalbekiroglu M, Geyik F (2016) Examining the relation between the number and location of tuck stitches and bursting strength in circular knitted fabrics. Fibres and Textiles in Eastern Europe 24.

5. Emirhanova N, Kavusturan Y (2008) Effects of knit structure on the dimensional and physical properties of winter outerwear knitted fabrics. Fibres \& Textiles in Eastern Europe 16: 67

6. Nassif NAA (2013) A Study of the effects of machine gauge and some knit structures on the physical properties of weft knitted fabrics. IJSR 9: 5643-5649.

7. Islam M (2014) Effect of wale wise increasing of tuck and miss loops on bursting strength of single jersey fabric at grey and finish state. IJRET 3: 286-291.

8. Khoddami A, Carr1 CM, Gong RH (2009) Effect of hollow polyester fibres on mechanical properties of knitted wool/polyester fabrics. Fibers and Polymers. 10: $452-460$.

9. Bahl M, Arora C (2010) Milkweed blended fabric- A novel approach. PhD Thesis. Delhi: University of Delhi, 2010.

10. Hossain I (2016) Predicting the mechanical properties of viscose/lycra knitted fabrics using fuzzy technique, hindawi publishing corporation. Advances in Fuzzy Systems 2016: 1-9.

11. Akaydina M (2009) Characteristics of fabrics knitted with basic knitting structures from combed ring and compact yarns. IJFTR 34: 26-30.

12. Yesmin S (2014) Effect of stitch length and fabric constructions on dimensional and mechanical properties of knitted fabrics. World Appl Sci J 32: 1991-1995.

13. Mahisha SS, Patra AK, Thakur R (2012) Functional properties of bamboo/ polyester blended knitted apparel fabrics. Ind J Fibre \& Textile Res 37: 231-237.

14. Pant S, Jain R (2014) Comfort and mechanical properties of cotton and cotton blended knitted khadi fabrics. Stud Home Com Sci 8: 69-74.

15. Megeid ZMA, Al-bakry M, Ezzat M (2011) The influence of stitch length of weft knitted fabrics on the sewability. J American Sci 7: 610-617. 